Cite this article: Miricescu D, Totan A, Calenic B, Mocanu B, Greabu M. Salivary and serum enzymes as diagnostic biomarkers in patients with periodontal disease. Stoma Edu J. 2014; 1(1):22-27.

\title{
SALIVARY AND SERUM ENZYMESAS DIAGNOSTIC BIOMARKERS IN PATIENTS WITH PERIODONTAL DISEASE
}

https://doi.org/10.25241/stomaeduj.2014.1(1).art.4

\section{Daniela Miricescu ${ }^{19}$, Alexandra Totan ${ }^{1 b}$, Bogdan Calenic'c, Brânduşa Mocanuc, Maria Greabu ${ }^{1 \mathrm{~d} *}$}

1. Department of Biochemistry, Faculty of Dental Medicine, "Carol Davila" University of Medicine and Pharmacy, Bucharest, Romania 2. Department of Periodontology, Faculty of Dental Medicine, "Carol Davila" University of Medicine and Pharmacy, Bucharest, Romania a. PhD, Teaching Assistant b. PhD, Lecturer

c. DDs, PhD, Teaching Assistant d. PhD, Professor, Head of Department
Received: 11 December 2013 Accepted: 15 January 2014

\footnotetext{
* Corresponding author:

Professor Maria Greabu, PhD, Head of Department Department of Biochemistry, Faculty of Dental Medicine "Carol Davila" University of Medicine and Pharmacy, Bucharest, Romania 8 Blvd. Eroii Sanitari, Sector 5, RO-050474 Bucharest, Romania Tel: +40755044047, Fax: +40213110984 e-mail: mariagreabu@yahoo.com
}

\section{Abstract}

Introduction: Periodontitis is a common oral affection characterized by inflammation, connective tissue breakdown and, finally, alveolar bone loss. One feature of the inflammatory process is the release of enzymes from different oral tissues. The general aim of the present study was to detect salivary and serum enzyme levels in patients with periodontitis.

Methodology: We included 20 patients with chronic periodontitis and 20 controls. Unstimulated whole saliva and serum was used to detect the enzymes employing the kinetic method and an automatic analyzer. Patients and healthy controls were investigated for plaque index (PI), bleeding index (GI) and probing depth (PD) $(p<0.05)$. The following enzymes were analyzed: aspartate aminotransferase (AST), lactate dehydrogenase (LDH), alkaline phosphatase (ALP) and gamaglutamil transferase (GGT).

Results: The saliva of patients with periodontal disease presented significantly decreased levels of LDH and ALP. Significantly increased levels of serum ALP and GGT were observed in patients with periodontal disease. At the same time no statistical difference was found between controls and periodontitis patients for AST and LDH. Also salivary levels for GGT were decreased, while for AST the levels were increased but the difference was not statistically significant.

Conclusion: The activity of these enzymes in the saliva and serum of patients with periodontal disease may represent a useful tool in diagnosing, monitoring and treating chronic periodontitis.

Keywords: saliva, aspartate aminotransferase, lactate dehydrogenase, alkaline phosphatase, gamaglutamil transferase, periodontitis.

\section{Introduction}

Whole saliva is secreted by three major and many minor salivary glands. It contains locally produced biomolecules as well as other molecules derived from the systemic circulation. Whole saliva can contain proteins, serum products, electrolytes, immune and epithelial cells and gingival crevicular fluid (GCF) $(1,2)$. Periodontal disease is one of the most widespread oral diseases. It is a chronic bacterial infection characterized by inflammation, connective tissue breakdown and, finally, alveolar bone loss (3). Following general inflammatory processes, periodontal affections are characterized by the release of enzymes from stromal, bacterial, inflammatory and epithelial cells (4). These intracellular enzymes are released from damaged cells in the periodontal tissues into the GCF, saliva and surrounding fluids (4). Studies show that the most important enzymes involved in the process include: aspartate and alanine aminotransferases (AST and ALT), lactate dehydrogenase (LDH), alkaline phosphatase (ALP), gamaglutamil transferase (GGT), creatine kinase (CK) and acidic phosphatase (PAP) (4-6). However, to date, there is limited data on the levels of these enzymes in the saliva and serum of patients with periodontal diseases. The main aim of our study was to detect the activities of AST, LDH, ALP and GGT in the saliva and serum of patients with periodontal disease.

\section{Methods}

\section{Patients}

This study was reviewed and approved by the ethics board of the "Carol Davila" University of Medicine and Pharmacy, Faculty of Dental Medicine. Informed consent was obtained 
Table 1. Clinical parameters for periodontal disease

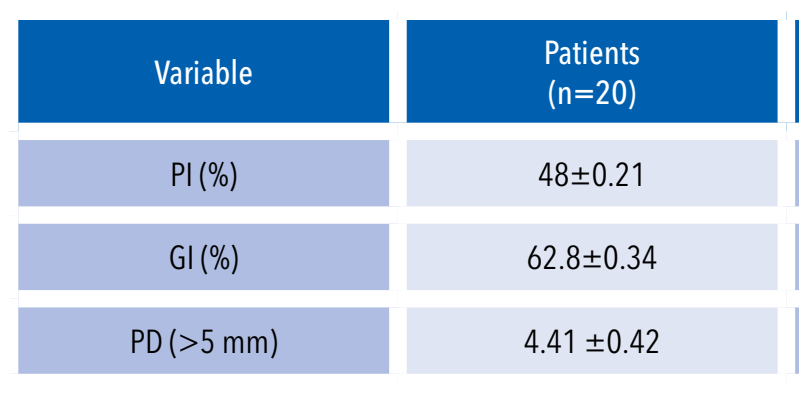

from each participant who agreed to participate voluntarily in this study. The study was carried in 20 patients with chronic periodontitis (5 males and 15 females; mean age $51.26 \pm 7.4$ years). Twenty healthy subjects with no gingival inflammation, good oral hygiene and no history of periodontal disease were grouped as controls. All patients included in the study fulfilled the following criteria: absence of any systemic disease; no use of systemic medications like antibiotics within the preceding three months, anti-inflammatory drugs or anti-oxidant drugs, no history of tobacco usage or alcoholism. Periodontal status was determined by measuring PD (probing depth), gingival index (GI) and plaque index (PI).

\section{Saliva sampling}

The subjects included in this study were told not to eat or drink anything in the morning before the collection of the samples. Unstimulated whole saliva was collected into sterile tubes between 9 and 10 a.m. after a single mouth rinse with $10 \mathrm{~mL}$ of distilled water to wash out exfoliated cells. About $2 \mathrm{~mL}$ of unstimulated whole saliva collected was immediately centrifuged at $3000 \mathrm{rpm}$ for $10 \mathrm{~min}$ to remove cell debris. The supernatant was kept and stored in small aliquots at $-80^{\circ} \mathrm{C}$ until further analysis.

\section{Serum sampling}

At the same time, $5 \mathrm{ml}$ of blood were collected and the serum obtained was used for our determinations. All biomarkers were performed using the kinetic method at an automatic analyzer (A15 Biosystems, Spain).

\section{Serum and salivary AST}

AST catalyzes the transfer of amino groups from the aspartate molecule to 2-oxoglutarate, forming oxaloacetate and glutamate. Enzyme activity is determined by measuring the decrease in NADH concentration at $340 \mathrm{~nm}$ through the reaction catalyzed by malate dehydrogenase (MDH).

Chemical reaction: Aspartam+2-oxoglutarate $\rightarrow$ glutamate + oxaloacetate

Oxaloacetate $+\mathrm{NADH}+\mathrm{H}^{+} \rightarrow \mathrm{L}$-malate $+\mathrm{NAD}^{+}$

\section{Salivary and serum assay for ALP}

Under the action of ALP, p-nitrophenilphosphate (colorless) is converted to p-nitrophenol, the yellow colored compound. The color intensity is proportional to the activity of ALP in the sample.

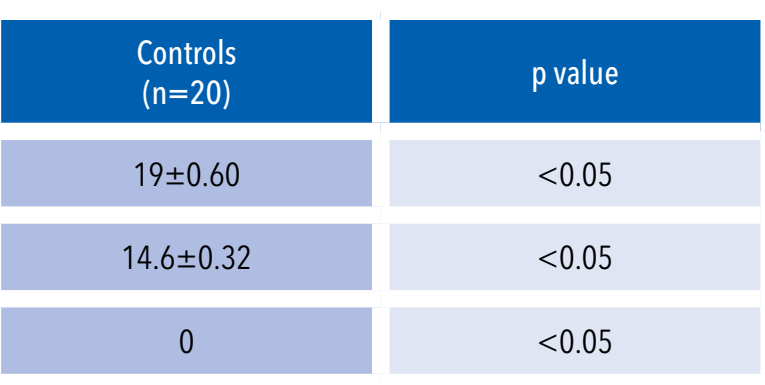

Chemical reaction: $p$-Nitro-phenylphosphate + $\mathrm{H}_{2} \mathrm{O} \rightarrow \mathrm{p}$-Nitrophenol + Phosphate

Salivary and serum assay for LDH

Chemical reaction: L-lactate + pyruvate $+\mathrm{NAD}^{+}$ $\leftarrow \rightarrow \mathrm{NADH}+\mathrm{H}^{+}$

\section{Salivary and serum assay for GGT}

GGT catalyzes the transfer of $\gamma$-glutamate from L- $\gamma$-glutamyl-3-carboxy-4-nitroanilide in glycylglycine to form $\mathrm{L}-\gamma$-glutamilglicilglicine and 5-amino-2-nitrobenzene yellow. The absorbance is read at $405 \mathrm{~nm}$.

\section{Chemical reaction:}

L- - -glutamyl-3-carboxy-4 nitroanilide + glycylglycine $\rightarrow \mathrm{L}-\gamma$ glutamilglicilglicine +5 amino 2-nitrobenzene.

\section{Statistical analysis}

Data distributions were expressed as means, standard deviations (SD), ranges, and percentages, as appropriate. The Pearson's correlation coefficient and ANOVA test were used. The data were analyzed statistically on the computer using StatalC 11 (StataCorp. 2009. Stata: Release 11. StatisticalSoftware. College Station, TX, USA). A $p$-value $<0.05$ was considered statistically significant.

\section{Results}

Patients and healthy controls were investigated for plaque index $(\mathrm{PI})$, bleeding index $(\mathrm{Gl})$, and probing depth (PD) $(p<0.05)$. Results are detailed in Table 1.

In the saliva of patients with chronic periodontitis, significantly decreased levels of LDH and ALP were detected. The salivary level of GGT was decreased and the salivary level of AST was increased but both were not statistically significant (Table 2).

Significantly increased levels for serum ALP and GGT were obtained from patients with periodontal disease. Increased serum levels for AST and LDH were also found (Table 3).

\section{Discussion}

During the past few decades, many biomarkers have been proposed for the diagnosis of periodontal disease, such as intracellular enzymes. Their activity can be detected in unstimulated saliva and in GCF. If the periodontal tissue is damaged or if the cells are affected due to edema or cellular damage, intracellular enzymes are 
Table 2. Salivary levels

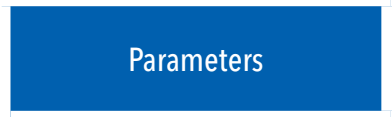

LDH U/mg proteins
ALP U/mg proteins

GGT U/mg proteins

AST U/mg proteins

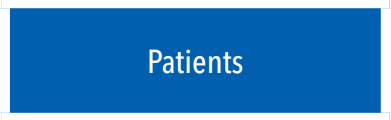

$102,89 \pm 96$

$24,76 \pm 25,81$

6,81

$20,31 \pm 25,65$

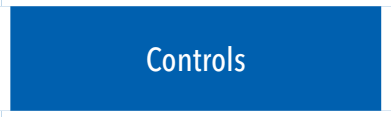

179,06

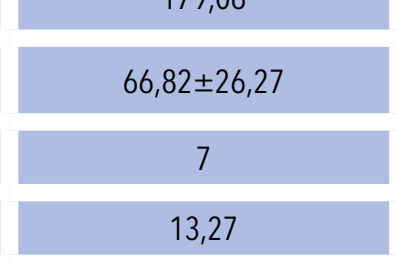

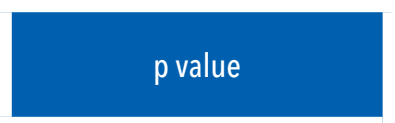

$<0.005$

$<0.005$

$<0.3$

$<0.43$

Table 3. Serum levels from patients with periodontal disease

\begin{tabular}{|c|}
\hline Parameters \\
\hline LDH U/L \\
\hline ALP U/L \\
\hline GGT U/L \\
AST U/L
\end{tabular}

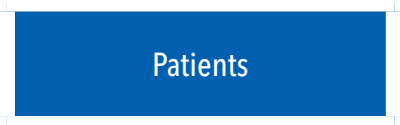

\begin{tabular}{|r|}
\hline $261,83 \pm 45,97$ \\
\hline $56,5 \pm 20,04$ \\
\hline $25,33 \pm 8,64$ \\
\hline $15,15 \pm 16,78$ \\
\hline
\end{tabular}

released into the GCF and saliva $(4,7)$. LDH, AST, and GGT are intracellular enzymes also present in oral soft tissues. Their activity is increased in saliva as a consequence of release from damaged cells in the periodontal soft tissue and inflamed gums. In our study, these enzymes have been detected in unstimulated whole saliva (8). ALP is an intracellular enzyme present predominantly in the bone, being the first enzyme determined in periodontal disease $(7,8)$. Dabra et al. detected an increased level of this enzyme in the stimulated saliva of patients with periodontal disease (6). Todorovic et al. also reported an increased activity of ALP in the unstimulated saliva of 187 patients with periodontal disease (4). In our study we obtained a statistically significant decrease of salivary ALP in patients with periodontal disease compared to the healthy patients group. Studies have shown a remarkable increase of this enzyme in the acute phase of periodontal disease (7-10). Increased activity in saliva is probably a consequence of the destructive processes in the alveolar bone in advanced stages of periodontal disease. Yan $F$ et al. considered that ALP was increased in the acute phase of periodontal disease, suggesting that the periodontal disease is well advanced (11). The salivary enzymatic activity of ALP significantly decreases during periodontal ligament attachment loss and bone resorption. Release of cytokines (IL$1 \beta$ ) during bone resorption may inhibit proliferation of periodontal ligament cells such as osteoblasts (12). The LDH level was also significantly decreased in the saliva of patients with periodontal disease compared to healthy patients group. Zappacosta
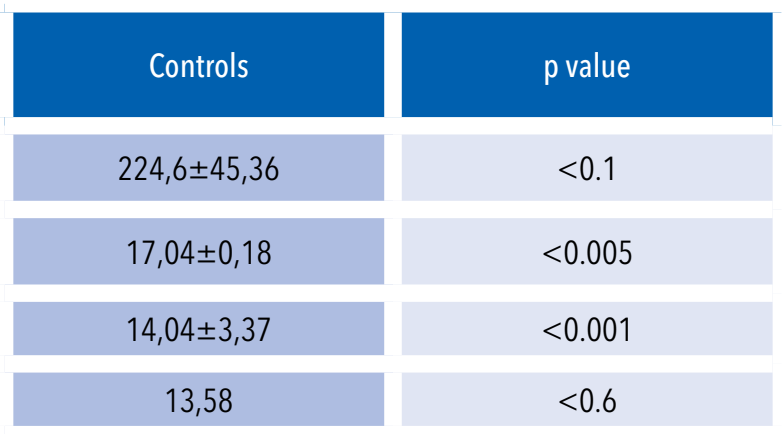

et al. detected an increased salivary level of LDH in patients with periodontal probing pocket depth $>5 \mathrm{~mm}$ (13). Atici et al. measured LDH in GCF and observed that the progression of periodontal disease is associated with this enzyme (14). GGT is a key enzyme which can be regarded as a new important oxidative stress biomarker and a indicator of cellular damage $(8,15)$. Dabra et al. detected an increased level of GGT in stimulated saliva of patients with periodontal disease (6). Todorovic et al. obtained an increased level of GGT in unstimulated saliva. In our study we detected decreased levels of GGT but without a statistically significant difference (4). The decreased level of GGT, may reflect the presence of oral oxidative stress in patients with periodontitis. The only enzyme that showed increased levels in unstimulated whole saliva of patients with periodontitis was AST. Increased levels of AST were also reported by Todorovic et al. in unstimulated saliva of patients with periodontal disease (4). The results obtained in our study may have several explanations: after determining these intracellular enzymes patients included in the study may or may not have been in an advanced stage of periodontal disease. At the time of collection of the biological samples, it is possible that patients were in different stages of periodontal disease. Our study used unstimulated whole saliva vs GCF because saliva collection has several clear advantages: no need for specialized equipment or techniques, much faster and more convenient for both the patient and the medical staff. Because whole saliva contains numerous biomarkers derived from all the structures of the 
oral cavity, analyzing biomarkers in saliva may provide a thorough overview of the periodontal status compared with GCF. Studies show that different results are due primarily to different processing methods for the saliva. Therefore the study design requires careful standardization in the collection and processing of saliva. Numerous studies show that there is a direct relationship between periodontal complications and many systemic diseases such as cardiovascular disease, metabolic syndrome or diabetes (16-20). Another aim of the present study was to test the hypothesis that periodontal disease can influence general health by analyzing enzymatic levels. In the serum of patients with periodontal disease we have obtained a series of changes in the enzymatic activity of ALP, LDH, GGT and AST in patients with periodontal disease when compared with the control group. ALP is present especially in bones and the liver, duodenum and kidney. Increased levels of this enzyme have been recorded in skeletal damage associated with osteoblastic reaction and cholestasis $(21,22)$. Our overall results show that the serum levels of the enzyme in patients with periodontal disease are statistically increased when compared to the control group. Previous studies show an association between periodontal disease and osteoporosis, especially in postmenopausal women $(23,24)$. Our group of patients with periodontal disease included 15 females with the average age of over 50 years so they present higher risk of osteoporosis. LDH is present especially in the muscle, liver, myocardium, kidney and erythrocytes. Marked increase of the enzyme activity of LDH is found in myocardial infarction, toxic liver damage or testicular cancer. Moderate increments of LDH were also found in muscle disease, hemolysis and malignant lymphoma $(22,25)$. In our experiments,

\section{Bibliography}

1. Miller CS, King CP, Chris-Langub Jr M, Kryscio J, Thomas MV: Salivary biomarkers of existing periodontal disease: A cross-sectional study. J Am Dent Assoc 2006, 137(3): 322-329. 2. Spielmann N, Wong DT: Saliva: diagnostics and therapeutic perspectives. Oral Dis 2011, 17(4):345-354.

3. Ridgeway EE: Periodontal disease: diagnosis and management. J Am Acad Nurse Pract 2000,12(3):79-84.

4. Todorov T, Dozic I, Barrero MV, Ljuskovic B, Pejovic J, Marjanovic M, Knezevic M: Salivary enzymes and periodontal disease. Med Oral Patol Oral Circ Bucal 2006, 11(2): E115-119.

5. Miller CS, Foley JD, Bailey AL, Campell CL, Humphries RL, Floriano NCP, Simmons G: Curent developments in salivary diagnostics. Biomarkers Med 2010, 4(1):171-189.

6. Dabra S, China K, Kaushik A: Salivary enzymes as diagnostic markers for detection of gingival/periodontal disease and their correlation with the severity of the disease. J Indian Soc Periodontol 2012, 16(3):358-364.

7. Kaufman E, Lamster I: Analysis of saliva for periodontal diagnosis. J Clin Periodontol 2000, 27(7):453-465.
LDH was increased but the increase was not statistically significant. This increase in LDH levels may be a warning sign even if it was not a statistically significant value. Beck and colleagues have postulated a connection between periodontal disease and atherosclerosis. As such, people suffering from periodontal disease may be at increased risk of atherosclerosis (26). GGT is present in the kidney, pancreas and liver. Significant increases of GGT activity have been recorded in cholestasis, alcoholism and hepatic tumors. Moderate increases were observed for chronic hepatitis and pancreatitis (22). In our experiments, GGT levels were statistically increased in the serum from patients with periodontal disease versus the healthy subjects. AST is a widespread enzyme, mainly localized in the liver, myocardium or muscle, but also present in small amounts in the lungs, kidneys, pancreas and erythrocytes. Marked increments of AST are present in myocardial infarction, acute hepatitis or toxic liver damage. Moderate increases are observed in patients with chronic hepatitis and infectious mononucleosis (22,27). The enzymatic activity of AST was increased ( $p>0.05)$ in the serum of patients with periodontal disease versus the healthy group.

\section{Conclusion}

The salivary and serum enzymes detected in our study can be useful in the monitoring of patients with periodontal disease.

\section{Acknowledgements}

This study was supported by the Sectorial Operational Programme Human Programme Human Resources Development (SOP HRD), financed from the European Social Fund and by the Romanian Government under the contract number POSDRU/6/1.5/S/S17.

8. Ozmeric $\mathrm{N}$ : Advances in periodontal disease markers. Clin Chim Acta 2004, 343 (1-2):1-16.

9. Nomura Y, Shimada Y, Hanada N, Numabe Y, Kamoi K, Sato T, Gomi K, Arai T, Inagaki K, Fukuda M, Noguchi T, Yoshie H: Salivary biomarkers for predicting the progression of chronic periodontitis. Arch Oral Biol 2012, 57(4):413-420

10. Totan A, Greabu M, Totan C, Spinu T: Salivary aspartate aminotransferase, alanine aminotransferase and alkaline phoshatase: possible markers in periodontal diseases?. Clin Chem Lab Med 2006, 44(5):612-615.

11. Yan F: Alkaline phosphatise level in gingival crevicular fluid of periodontities before and after periodontal treatment. Chung Hua Kou Chiang Hseuch Tsa Chin 1995, 30(4):204-206, 255-256.

12. Agawal S, Chandra CS, Piesco NP, Langkamp HH, Bowen L, Baran C: Regulation of periodontal ligament cell functions by interleukin-1 beta. Infect Immun 1998, 66(3):932-937.

13. Zappacosta B, Manni A, Persichilli S, Boari A, Scribano D, Minucci A, Raffaelli L, Giardina B, De Sole P: Salivary thiols and 


\section{Bibliography}

enzyme markers of cell damage in periodontal disease. Clin Biochem 2007, 40(9-10):661-665.

14. Atici K, Yamalik N, Eratalay K, Etikan I: Analysis of gingival crevicular fluid intracytoplasmic enzyme activity in patients with adult periodontitis and rapidly progressive periodontitis. A logitudinbal study model with periodontal treatment. J Periodontol 1998, 69(10):1155-1163.

15. Battino M, Greabu M, Totan A, Bullon P, Tovaru S, Mohora M, Didilescu A, Parlatescu I, Spinu T, Totan C: Oxidative stress markers in oral lichen planus. Biofactors 2008, 33(4):301-310.

16. Esen C, Alkan BA, Kırnap M, Akgül O, Işıkoğlu S, Erel 0: The effects of chronic periodontitis and rheumatoid arthritis on serum and gingival crevicular fluid total antioxidant/ oxidant status and oxidative stress index. J Periodontol 2012, 83(6):773-779.

17. Bullon P, Cordero MD, Quiles JL, Ramirez-Tortosa Mdel C, Gonzalez-Alonso A, Alfonsi S, García-Marín R, de Miguel M, Battino M: Autophagy in periodontitis patients and gingival fibroblasts: unraveling the link between chronic diseases and inflammation. BMC Med 2012, 17;10:122.

18. Bullon P, Morillo JM, Ramirez-Tortosa MC, Quiles JL, Newman $\mathrm{HN}$, Battino M: Metabolic syndrome and periodontitis: is oxidative stress a common link?. J Dent Res 2009, 88(6):503-518.

19. Floriano PN, Christodoulides N, Miller CS, Ebersole JL, Spertus J, Rose BG, Kinane DF, Novak MJ, Steinhubl S, Acosta S, Mohanty S, Dharshan P, Yeh CK, Redding S, Furmaga W, McDevitt JT: Use of saliva -based nano-biochip tests for scutemyocardial infarction at the point of care: a feasibility study. Clin Chem 2009, 55(8):1530-1538.

20. Galli C, Passeri G, Macaluso GM: FoxOs, Wnts and oxidative stress-induced bone loss: new players in the periodontitis arena? J Periodontal Res 2011, 46(4):397-406.

21. Wiwanitkit V: High serum alkaline phosphatase levels, a study in 181 Thai adult hospitalized patients. BMC Fam Pract 2001,2:2.

22. Dobreanu M: Biochimie clinică. Implicații practice, Editia a II - a. Editura Medicală, 2010, Capitolul 12: 223-259.

23. Bullon $P$, Goberna B, Guerrero JM, Segura JJ, Perez-Cano R, Martinez-Sahuquillo A: Serum, saliva and gingival crevicular fluid: their relation to periodontal status and bone mineral density in postmenopausal woman. J Periodontol 2005, 76(4): 513-519.

24. Bullon P, Chandler L, Segura Egea JJ, Cano PR, Sahuquillo AM: Osteocalcin in serum, saliva and gingival crevicular fluid: their relation with periodontal treatment outcome in postmenopausal woman. Med Oral Patol Oral Cir Bucal 2007, 12(3):E193-197.

25. Kornberg A, Polliak A: Serum lactate dehydrogenase levels in acute leukemia. Marked elevations in lymphoblastic leukemia. Blood 1980, 56(3):351-355.

26. BeckJD, Slade G, OffenbacherS: Oral disease, cardiovascular disease and systemic inflammation. Periodontology 2000 2000, 23:110-120.

27. Annoni G, Chirillo R, Swanie D: Prognostic value of mitochondrial aspartate amniotrasferase in acute myocardial infarction. Clin Biochem 1986, 19(4): 235-239. 


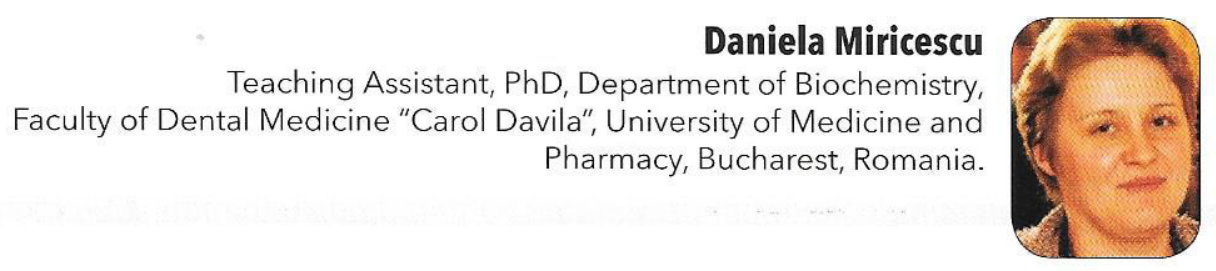

Her PhD, focused on the study oxidative stress as a new pathological biochemical mechanism in oral diseases, using saliva as a new

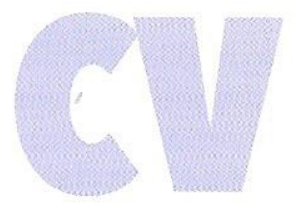
diagnostic fluid in oral diseases.

In the spring of 2011, during an exchange program, she worked at the Università Politecnica delle Marche, Italia, under the direct supervision of Maurizio Battino, PhD, DSc, MS, MD (Hon), focusing on the biochemical mechanisms of oxidative stress and antioxidants.

Her current research interests are, oxidative stress, oral stem cells properties, nanoparticles, and their possible interaction with the oral stem cells and generation of oxidative stress.

\section{Regarding this study:}

a. 40 patients were included in the study group

$\square$ b. The general aim of the present study was to detect ONLY the salivary enzyme activities

$\square$ c. no laboratory markers were studied

$\square$ d. Periodontal status was established using classic clinical parameters, plaque index, bleeding index and probing depth

\section{Regarding the plaque index (PI), bleeding index (GI) and probing depth (PD):}

a. all the results were statistically significant

$\square$ b. The PI in the study group was $48 \pm 0.21$

c. The $\mathrm{Gl}$ in the study group was $48 \pm 0.21$

$\square \mathrm{d}$. The PD in the study group was $48 \pm 0.21$

\section{Regarding the salivary levels:}

$\square$ a. The LDH in the patients was $102,89 \pm 96$

$\square$ b. The ALP in the patients was $102,89 \pm 96$

$\square$ c. The GGT in the patients was $102,89 \pm 96$

$\square \mathrm{d}$. The AST in the patients was $102,89 \pm 96$

\section{Regarding the serum levels from patients with periodontal disease:}

a. The LDH in the patients was $25,33 \pm 8,64$

$\square$ b. The ALP in the patients was $25,33 \pm 8,64$

$\square$ c. The GGT in the patients was $25,33 \pm 8,64$

$\square \mathrm{d}$. The AST in the patients was $25,33 \pm 8,64$ 